\title{
Demographics and Clinical Characteristics of Open- Globe Ocular Trauma at a Tertiary Eye Center in the Philippines: A 5-Year Retrospective Review
}

\author{
Jacoba Cris Martin* \\ Department of Ophthalmology, East Avenue Medical Center, Philippines
}

*Corresponding author: Jacoba Cris Martin, Department of Ophthalmology, East Avenue Medical Center, Philippines.

Received Date: February 04, 2020

Published Date: February 19, 2020

\section{Abstract}

Objective: To describe the demographics and clinical characteristics associated with visual acuity (VA) in open-globe trauma patients at a tertiary eye center in the Philippines.

Design and Methods: A retrospective cohort study of 445 patient records from January 2013 to November 2017 was done. All openglobe injuries, defined by Birmingham Eye Trauma Terminology classification system, were included [1]. Data about demographics and clinical characteristics were collected. Baseline VA was compared to last follow-up VA, classified as excellent ( $>20 / 60)$, good (20/80 to 20/200) or poor $(<20 / 200)$.

Results: The mean age of patients was $28.0 \pm 16.9$ years. The most common objects causing injury were hammered nails at work $(57 / 232$ [24.6\%]) while for children 8 years and younger they were knives at home (7/34 [20.6\%]). The most common complication was intraocular foreign body (IOFB) (27/107 [25.2\%]). Subgroup analysis was done on patients with at least 1-month follow-up, with mean follow-up time of $105.5 \pm 259$ days. At final consult 59.6\% (84/141) had excellent outcome, 12.8\% (18/141) had good outcome, and 27.7\% (39/141) had poor outcome. For complications, VA improved significantly between initial and last consult for eyes with vitreous hemorrhage (LogMAR $1.87 \pm 0.83$ vs $1.40 \pm 1.00$; $\mathrm{p}=0.022$ ), IOFB ( $\log M A R 1.69 \pm 0.91$ vs $1.10 \pm 0.98 ; p=0.011$ ) and eyes needing penetrating keratoplasty (LogMAR $2.07 \pm 0.68$ vs $1.22 \pm 0.94 ; p=0.007$ ). There was no significant improvement in VA for eyes presenting with retinal detachment and endophthalmitis. Better initial VA correlated with excellent final VA $(\mathrm{p}<0.006,0 \mathrm{R}=1.131,95 \% \mathrm{CI}=0.331,1.930)$.

Conclusion: Ocular trauma continues to be a common cause of preventable blindness in the Philippines, most commonly seen at the workplace. Prognosis and management of patients should be based on initial VA, and other pertinent clinical characteristics.

Keywords: Open globe; Trauma; Public health; Birmingham eye trauma classification system; BETT; Visual outcomes

\section{Introduction}

Global data reports 55 million eye injuries per year-resulting in 1.6 million blind and 2.3 million visually impaired [2] Of these injuries, $8.9 \%-67 \%$ are open-globe amounting to around 3.5$3.75 / 100,000$ per year [3]. In the Philippines, there is a lack of enough data similar to international publications. The purpose of this study is to describe the demographics and clinical characteristics associated with visual acuity (VA) in globe trauma patients, and to analyze their visual potential based on clinical presentation. Ocular trauma is a common cause of morbidity in the country; thus, data is critical for policymaking and resource allocation.

\section{Methodology}

The study is a retrospective cohort study of 445 patients with open globe trauma seen at both the ophthalmology outpatient (OPD) department and emergency room of the East Avenue Medical Center from January 2013 to November 2017. All open globe eye injuries defined by Birmingham Eye Trauma Terminology (BETT) classification system were included [1]. Patients treated in other institutions before consult at East Avenue Medical Center were excluded. Subgroup analysis of patients who had at least 1 month of follow-up at the OPD was done. 
The following data were retrieved from the records:

1. Demographics and Population Description: Age, sex, city and province of incident

2. Nature of Injury: Consult date, primary diagnosis, laterality, time of incident, time to consult, place of incident, intention of injury, object causing injury, mechanism of injury

3. Physical Examination: VA at initial consult using LogMAR scale [4], zone of injury based on the Ocular Trauma Classification Group classification system [5], affectation of central 3mm of visual axis, corneal wound length, scleral wound length, uveal prolapse, hyphema, anterior chamber reaction, lens involvement, posterior involvement, complications

4. Procedures: Type of primary surgical repair, time to first surgery, anesthesia used, need for 2nd or 3rd procedure, enucleation/evisceration

5. Outcome: Follow-up VA (at 1, 3, 6 months; 1 year; then annually) and VA on last follow-up classified as excellent ( $>20 / 60$ ), good $(20 / 80$ to $20 / 200)$ or poor $(<20 / 200)$

\section{Statistical Methods}

All valid data from evaluable subjects were included in the analysis. Missing values were accounted for during the statistical analysis of outcome variables. Checks for homogeneity of sample population and normality assumption were performed. Summary statistics of quantitative outcome measures were reported as mean \pm standard deviation for normal distributions, or median (interquartile range) for skewed distributions. Qualitative measures (e.g. gender, success rate, complications) were presented as count (percent). Paired t-test was used to compare mean VA between baseline and last follow- up visit. Analysis of variance or Kruskal Wallis test was used to compare averages across surgery, type of injury and outcome. Chi-square test or Yate's chi square test was used to compare proportions. Ordinal regression analysis was used to determine factors correlated with outcome. Odds-ratio and $95 \%$ confidence intervals were estimated. Statistical significance was based on $p$-value $\leq 0.05$. STATA v13 was used in data processing and statistical analyses.

\section{Results}

Mean age of 445 cases of open-globe trauma was $28.0 \pm 17.0$ years, range from 10 months to 82 years. Open globe trauma was common among men (359/445, 82.9\%), young adults from 19-35 (156/445, 36.6\%) from industrial work premises (88/181, 48.6\%) and from the National Capital Region (NCR) (103/190, 54.2\%). Complete demographics are seen in Table 1 . There were more cases of open-globe trauma during the summer month of May, and the year-end months of September to December (Table 1) (Figure 1).

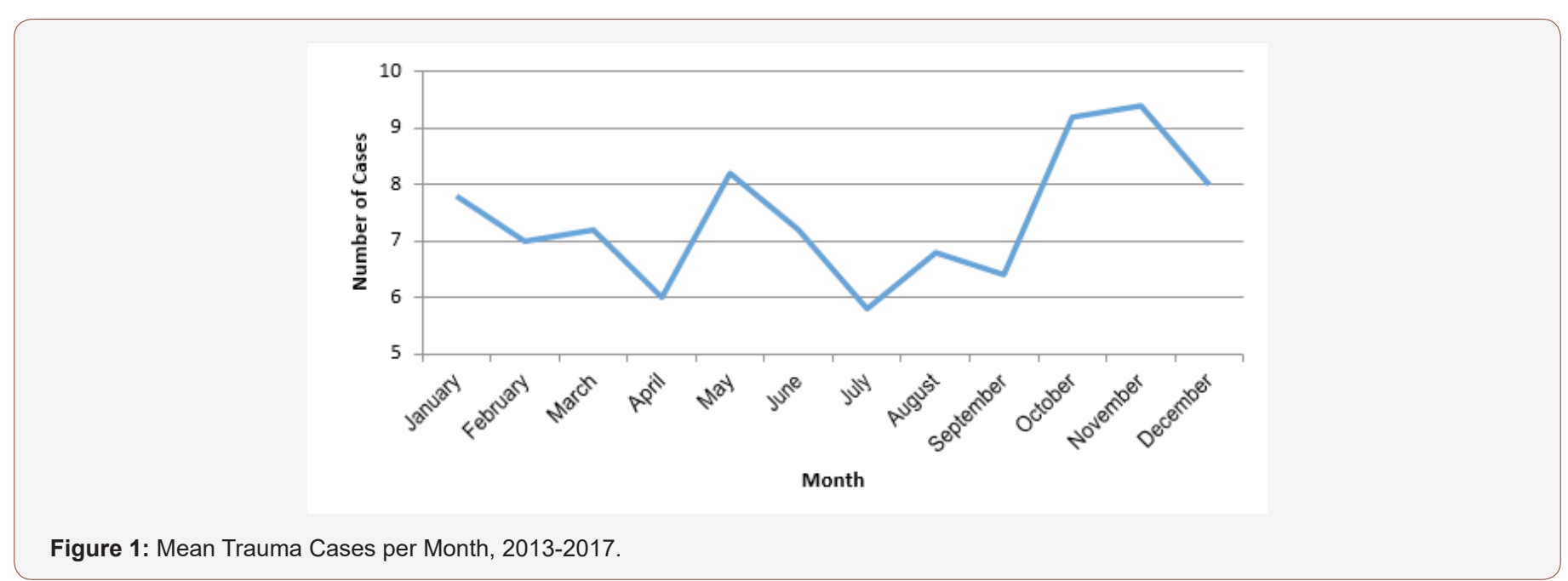

Table 1: Demographic characteristics of patients with open-globe trauma.

\begin{tabular}{|c|c|}
\hline \multicolumn{2}{|c|}{ Gender, n=445 } \\
\hline Male & $359(82.9 \%)$ \\
\hline Female & $74(17.1 \%)$ \\
\hline \multicolumn{2}{|c|}{ Age in Years, n=445 } \\
\hline Mean age, years & $28.0 \pm 17.0$ \\
\hline Pediatrics (<19) & $129(30.3 \%)$ \\
\hline Young adults (19-35) & $156(36.6 \%)$ \\
\hline Middle-aged adults (36-55) & $116(27.2 \%)$ \\
\hline Older adults (> 55) & $25(5.9 \%)$ \\
\hline
\end{tabular}




\begin{tabular}{|c|c|}
\hline Home & \multicolumn{2}{|c|}{ Place of Injury, n=181 $(39.2 \%)$} \\
\hline Industrial, work premises & $88(48.6 \%)$ \\
\hline Place of recreation, sport & $2(1.1 \%)$ \\
\hline Public building & $4(2.2 \%)$ \\
\hline Street, highway & $4(2.2 \%)$ \\
\hline Others & $12(6.7 \%)$ \\
\hline Torning (5:00am-11:59am) & $38(27.0 \%)$ \\
\hline Afternoon (12:00nn-6:59pm) & $69(48.9 \%)$ \\
\hline Evening (7:00pm-4:59am) & $34(24.1 \%)$ \\
\hline Assault & $17(9.8 \%)$ \\
\hline Self-inflicted & $2(1.1 \%)$ \\
\hline Unintentional & $155(89.1 \%)$ \\
\hline Average time from injury to consult, in days & $1(1), 0-197$ \\
\hline Average length of follow-up, in days & $105.5(259), 1-1518$ \\
\hline
\end{tabular}

Data presented as count (percent), mean \pm standard deviation or median (interquartile range), range

Corneal laceration was the most common open-globe ocular trauma $(282 / 445,63.4 \%)$. Accidents usually occurred in the afternoon, between noon and 7:00pm $(69 / 141,48.9 \%)$ with majority of cases unintentional $(155 / 174,89.1 \%)$. On average, patients took 1 day to consult after injury, range from 0 - 197 days. Hammered nails were the most common object causing injury for adults $(57 / 232$, $24.6 \%$ ) while for children 8 years and younger they involved knives

Table 2: Clinical characteristics of patients with open-globe trauma. at home (7/34, 20.6\%). There were 107 complications in 74 eyes noted in patients who followed-up at the OPD, with a complication rate of $42.5 \%$ (74/174). Most common complications were intraocular foreign body (IOFB) $(27 / 107,25.2 \%)$, vitreous hemorrhage (VH) $(22 / 107,20.6 \%)$ and retinal detachment (RD) $(16 / 107,15 \%)$ (Table 2\&3).

\begin{tabular}{|c|c|}
\hline \multicolumn{2}{|c|}{ Primary Diagnosis, $n=445$} \\
\hline Corneal laceration & $282(63.4 \%)$ \\
\hline Corneo-scleral laceration & $60(13.5 \%)$ \\
\hline Globe rupture & $28(6.3 \%)$ \\
\hline Scleral laceration & $47(10.6 \%)$ \\
\hline Sealed corneal laceration & $28(6.3 \%)$ \\
\hline \multicolumn{2}{|c|}{ Object Causing Injury, n=232 } \\
\hline Nails & $57(24.6 \%)$ \\
\hline Metal (Unspecified) & $27(11.6 \%)$ \\
\hline Broken Glass (Beverage Bottle) & $26(7.3 \%)$ \\
\hline Cement/Tile particles & $17(5.6 \%)$ \\
\hline Metal wire & $17(5.6 \%)$ \\
\hline Wooden stick (Barbecue/Tree Branch) & $14(6 \%)$ \\
\hline Others & $74(31.9 \%)$ \\
\hline \multicolumn{2}{|c|}{ Mechanism of Injury, $n=232$} \\
\hline Blunt & $27(11.6 \%)$ \\
\hline Burn & $1(0.4 \%)$ \\
\hline Missile & $3(1.3 \%)$ \\
\hline Sharp & $201(86.7 \%)$ \\
\hline \multicolumn{2}{|c|}{ Lens Status, $\mathrm{n}=445$} \\
\hline Intact & $364(81.8 \%)$ \\
\hline Traumatic cataract & $81(18.2 \%)$ \\
\hline
\end{tabular}




\begin{tabular}{|c|c|}
\hline \multicolumn{2}{|c|}{ Zone Involvement, $\mathbf{n = 1 5 0}$} \\
\hline Zone I & $113(75.3 \%)$ \\
\hline Zone II & $30(20.0 \%)$ \\
\hline Zone III & $7(4.7 \%)$ \\
\hline \multicolumn{2}{|c|}{ Posterior Involvement, $n=445$} \\
\hline With & $61(13.7 \%)$ \\
\hline Without & $384(86.3 \%)$ \\
\hline \multicolumn{2}{|c|}{ Central Affecting Injuries, $n=168$} \\
\hline With & $44(26.2 \%)$ \\
\hline Without & $124(73.8 \%)$ \\
\hline Mean corneal wound length & $4.8 \pm 2.9 \mathrm{~mm}$ \\
\hline Mean scleral wound length & $2.9 \pm 1.5 \mathrm{~mm}$ \\
\hline
\end{tabular}

Data presented as count (percent) or mean \pm standard deviation

Table 3: Complications.

\begin{tabular}{|c|c|}
\hline \multicolumn{2}{|c|}{ Number of Patients with Complications on Follow-up, n=174 } \\
\hline Present & $74(42.9 \%)$ \\
\hline Absent & $100(56.8 \%)$ \\
\hline Elevated IOP & \multicolumn{2}{|c|}{ Complications, n=107* } \\
\hline Endophthalmitis & $4(3.5 \%)$ \\
\hline Intraocular Foreign Body & $27(25.2 \%)$ \\
\hline Microbial Keratitis & $3(2.4 \%)$ \\
\hline Retinal Detachment & $15(14 \%)$ \\
\hline Vitreous Hemorrhage & $16(15 \%)$ \\
\hline Others & $22(20.6 \%)$ \\
\hline
\end{tabular}

Data presented as count (percent)

*One patient may have multiple complications

Mean VA improved from baseline to last follow-up among those with corneal laceration (LogMAR $1.57 \pm 0.94$ vs $0.88 \pm 0.96$; $\mathrm{p}<0.0001$ ) and corneo-scleral laceration (LogMAR $1.66 \pm 0.94$ vs $0.84 \pm 0.95 ; \mathrm{p}<0.0001)$. Globe rupture always presented with VA near no light perception (NLP) (Table 4). Mean VA significantly improved for patients with vitreous hemorrhage (LogMAR $1.87 \pm 0.83$ vs $1.40 \pm 1.00$; $\mathrm{p}=0.022$ ), intraocular foreign body (Log-
MAR 1.69 \pm 0.91 vs $1.10 \pm 0.98 ; p=0.011$ ) and patients needing corneal transplant (LogMAR $2.07 \pm 0.68$ vs $1.22 \pm 0.94 ; \mathrm{p}=0.007$ ). See Table 5 Temporal profile of patients by complication is seen in (Figure 2). There was a significant improvement in VA after removal of IOFB (LogMAR $1.76 \pm 0.84$ vs $1.06 \pm 0.95 ; \mathrm{p}=0.009$ ). There was no significant difference in VA after repair of RD. (LogMAR $1.79 \pm 0.95$ vs $1.66 \pm 0.23 ; \mathrm{p}=0.128$ ) (Figure 2) (Table 4,5,6).

Table 4: Mean visual acuity according to type of injury.

\begin{tabular}{|c|c|c|c|c|c|c|}
\hline & Corneal & Corneo- Scleral & Globe Rupture & Scleral & Sealed Corneal & P-Value \\
\hline Initial & $1.57 \pm 0.94$ & $1.66 \pm 0.94$ & 2.4 & $1.10 \pm 1.05$ & $1.18 \pm 0.98$ & $<0.0001^{*}$ \\
\hline Month 1 & $0.88 \pm 0.89$ & $1.02 \pm 0.93$ & 2.4 & $1.18 \pm 1.07$ & $1.00 \pm 1.04$ & 0.583 \\
\hline Month 3 & $0.91 \pm 0.94$ & $0.88 \pm 0.91$ & 2.5 & $1.20 \pm 1.16$ & $1.03 \quad 0.87$ & 0.859 \\
\hline Month 6 & $0.81 \pm 0.92$ & $1.40 \pm 1.02$ & 2.5 & $0.97 \pm 1.13$ & 0.2 & 0.56 \\
\hline \multirow{3}{*}{$\begin{array}{c}\text { Month } 12 \text { Month } 24 \text { Last } \\
\text { consult }\end{array}$} & $0.97 \pm 0.95$ & $1.07 \pm 1.00$ & 2.5 & $1.77 \pm 0.64$ & - & 0.51 \\
\hline & $1.07 \pm 0.96$ & $1.57 \pm 1.36$ & 2.5 & - & - & 0.456 \\
\hline & $0.88 \pm 0.96$ & $0.84 \pm 0.95$ & 2.5 & $1.01 \pm 1.09$ & $1.09 \pm 0.96$ & 0.12 \\
\hline \multirow{2}{*}{$\begin{array}{l}\text { Initial vs Last consult } \\
\qquad \mathrm{p} \text {-value }\end{array}$} & $0.57 \pm 0.12$ & $0.91 \pm 0.19$ & - & $0.14 \pm 0.09$ & $0.26 \pm 0.72$ & \\
\hline & $<0.0001^{*}$ & $<0.0001^{*}$ & - & 0.144 & 0.334 & \\
\hline
\end{tabular}

Data presented as mean \pm standard deviation or mean difference \pm standard error

*Significant at $5 \%$ level 
Table 5: Mean visual acuity according to complication.

\begin{tabular}{|c|c|c|c|c|c|c|c|}
\hline & RD & VH & IOFB & ENDOPH & PK & IOP & OTH \\
\hline Initial Month 1 & $1.88 \pm 0.90^{*}$ & $1.87 \pm 0.83^{*}$ & $1.69 \pm 0.91^{*}$ & $1.58 \pm 1.04$ & $2.07 \pm 0.68^{*}$ & $2.26 \pm 1.15^{*}$ & $1.61 \pm 1.01$ \\
\hline Month 3 & $1.79 \pm 0.92^{*}$ & $1.40 \pm 0.96$ & $1.22 \pm 0.92$ & $1.95 \pm 0.97^{*}$ & $1.88 \pm 0.64^{*}$ & $1.29 \pm 0.72$ & $1.61 \pm 1.05$ \\
\hline Month 6 & $1.75 \pm 1.01^{*}$ & $1.40 \pm 0.95$ & $0.96 \pm 0.91$ & $1.92 \pm 0.85^{*}$ & $1.51 \pm 0.86^{*}$ & $1.03 \pm 0.92$ & $1.67 \pm 1.03$ \\
\hline Month 12 & $1.86 \pm 0.95^{*}$ & $0.96 \pm 0.92$ & $1.18 \pm 1.00$ & $1.88 \pm 0.95$ & $1.51 \pm 0.94$ & $1.30 \pm 1.12$ & $0.97 \pm 1.05$ \\
\hline \multirow{2}{*}{$\begin{array}{c}\text { Month 24 Last } \\
\text { consult }\end{array}$} & $2.36 \pm 0.09^{*}$ & $1.13 \pm 1.02$ & $0.72 \pm 1.07$ & $1.90 \pm 1.02$ & $1.38 \pm 0.90$ & $2.40 \pm 0.14$ & $1.27 \pm 1.07^{*}$ \\
\cline { 2 - 8 } & $2.42 \pm 0.10^{*}$ & - & - & - & - & - & - \\
\hline \multirow{2}{*}{$\begin{array}{c}\text { Initial vs Last con- } \\
\text { sult, p-value }\end{array}$} & $1.78 \pm 0.95^{*}$ & $1.40 \pm 1.00^{*}$ & $1.10 \pm 0.98$ & $2.15 \pm 0.44^{*}$ & $1.22 \pm 0.94$ & $0.91 \pm 1.04$ & $1.48 \pm 1.06$ \\
\cline { 2 - 8 } & $0.32 \pm 0.20$ & $0.52 \pm 0.20$ & $0.54 \pm 0.19$ & $-0.58 \pm 0.64$ & $0.82 \pm 0.24$ & $1.02 \pm 0.44$ & \\
\end{tabular}

RD: Retinal detachment; VH: Vitreous hemorrhage; IOFB: Intraocular foreign body; ENDOPH: Endophthalmitis; PK: For penetrating keratoplasty; IOP: Increased intraocular pressure; OTH: Other complications

*Significant at $5 \%$ level

Table 6: Mean visual acuity of patients who underwent posterior segment surgeries.

\begin{tabular}{|c|c|c|}
\hline & Repair of Retinal Detachment & Removal of =Intraocular Foreign Body \\
\hline Initial & $1.79 \pm 0.95$ & $1.76 \pm 0.84$ \\
\hline Month 1 & $1.74 \pm 0.94$ & $1.26 \pm 0.92$ \\
\hline Month 3 & $1.75 \pm 1.01$ & $0.96 \pm 0.91$ \\
\hline Month 6 & $1.86 \pm 0.95$ & $1.08 \pm 0.98$ \\
\hline Month 12 & $2.36 \pm 0.09$ & $0.72 \pm 1.07$ \\
\hline Month 24 & $2.40 \pm 0.10$ & - \\
\hline Last consult & $1.66 \pm 0.99$ & $1.06 \pm 0.95$ \\
\hline Initial vs last consult & $0.39 \pm 0.23$ & $0.67 \pm 0.22$ \\
\hline P-value & 0.128 & $0.009 *$ \\
\hline
\end{tabular}

Data presented as mean \pm standard deviation or mean difference \pm standard error

*Significant at $5 \%$ level

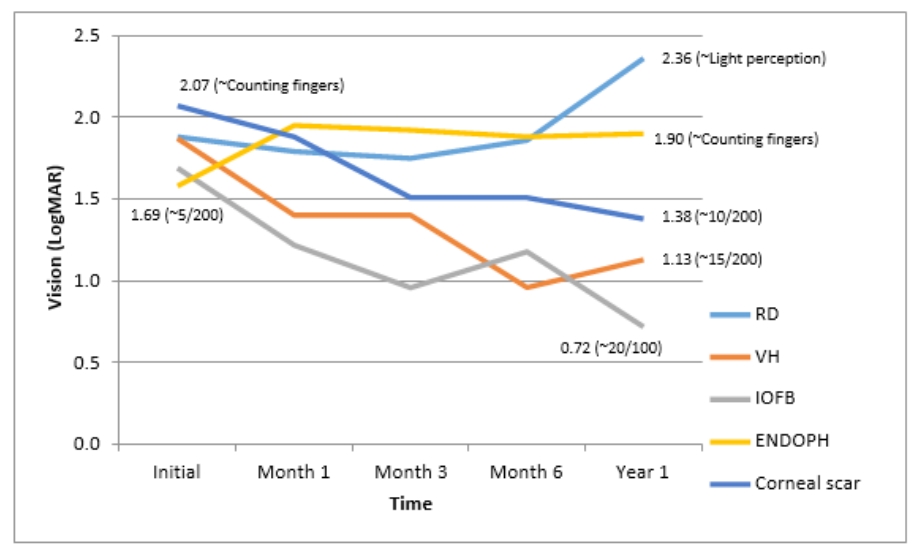

Figure 2: Temporal profile of patients by complication.

Among patients with at least 1 month of follow-up, at last visit $59.6 \%(84 / 141)$ had excellent outcome, $12.8 \%$ (18/141) had good outcome, and $27.7 \%$ (39/141) had poor outcome. Cases were significantly different across visual outcome with respect to VA at baseline $(p<0.0001)$, posterior involvement $(p<0.0001)$, anesthesia used during surgery $(\mathrm{p}=0.009)$, presence of retinal detach- ment $(p=0.003)$, endophthalmitis $(p=0.012)$, subspecialty referral $(p<0.0001)$, particularly referral to the retina clinic $(p<0.0001)$. (Table 7) Results of ordinal regression showed that better initial VA contributed to excellent final VA $(\mathrm{p}<0.006,0 R=1.131,95 \%$ $\mathrm{CI}=0.331,1.930)$. (Table 7). 
Table 7: Demographic and clinical characteristics patients with open-globe trauma by outcome at last follow-up.

\begin{tabular}{|c|c|c|c|c|}
\hline & Excellent $n=84$ & Good $n=18$ & Poor $n=39$ & p-value \\
\hline \multicolumn{5}{|c|}{ Initial Visual Acuity } \\
\hline$>20 / 60$ & $49(58.3 \%)$ & $1(5.6 \%)$ & $1(2.5 \%)$ & $<0.0001^{*}$ \\
\hline $20 / 80-20 / 200$ & $9(10.7 \%)$ & $4(22.2 \%)$ & $1(2.5 \%)$ & - \\
\hline$<20 / 200$ & $26(31.0 \%)$ & $13(72.2 \%)$ & $30(94.9 \%)$ & - \\
\hline \multicolumn{5}{|c|}{ Place } \\
\hline Industry, work premises & $15(30.0 \%)$ & $3(37.5 \%)$ & $11(42.3 \%)$ & 0.322 \\
\hline Home & $32(64.0 \%)$ & $4(50.0 \%)$ & $11(42.3 \%)$ & - \\
\hline Others & $3(4.5 \%)$ & $1(7.7 \%)$ & $4(12.1 \%)$ & - \\
\hline \multicolumn{5}{|c|}{ Intent } \\
\hline Assault & $3(4.5 \%)$ & $1(7.7 \%)$ & $4(12.1 \%)$ & 0.3 \\
\hline Unintentional & $63(95.5 \%)$ & $12(92.3 \%)$ & $29(87.9 \%)$ & - \\
\hline \multicolumn{5}{|c|}{ Zone } \\
\hline I & $60(76.9 \%)$ & $14(82.4 \%)$ & $23(67.6 \%)$ & 0.678 \\
\hline II & $15(19.2 \%)$ & $3(17.6 \%)$ & $8(23.5 \%)$ & - \\
\hline III & $3(3.8 \%)$ & - & $3(8.8 \%)$ & - \\
\hline \multicolumn{5}{|c|}{ Corneal Wound Length in $\mathrm{mm}$} \\
\hline & Excellent $\mathrm{n}=84$ & Good $n=18$ & Poor n = 39 & p-value \\
\hline$\leq 10$ & $28(93.3 \%)$ & $3(60.0 \%)$ & $13(92.9 \%)$ & 0.123 \\
\hline$>10$ & $2(6.7 \%)$ & $2(40.0 \%)$ & $1(7.1 \%)$ & - \\
\hline \multicolumn{5}{|c|}{ Scleral Wound Length in mm } \\
\hline$\leq 10$ & $9(100 \%)$ & $2(100 \%)$ & $4(100 \%)$ & 0.898 \\
\hline \multicolumn{5}{|c|}{ Central 3mm } \\
\hline Yes & $17(20.2 \%)$ & $6(33.3 \%)$ & $14(36.8 \%)$ & 0.117 \\
\hline No & $67(79.8 \%)$ & $12(66.7 \%)$ & $24(63.2 \%)$ & - \\
\hline \multicolumn{5}{|c|}{ Mechanism of Injury } \\
\hline Blunt & $7(10.8 \%)$ & $3(18.8 \%)$ & $4(11.4 \%)$ & 0.668 \\
\hline Missile & $3(4.6 \%)$ & - & - & - \\
\hline Sharp & $55(84.6 \%)$ & $13(81.2 \%)$ & $31(88.6 \%)$ & - \\
\hline \multicolumn{5}{|c|}{ Posterior Involvement } \\
\hline With & $19(22.6 \%)$ & $4(22.2 \%)$ & $25(65.8 \%)$ & $<0.0001^{*}$ \\
\hline Without & $65(77.4 \%)$ & $14(77.8 \%)$ & $13(34.2 \%)$ & - \\
\hline \multicolumn{5}{|c|}{ Anesthesia Used } \\
\hline General & $13(24.1 \%)$ & $8(50.0 \%)$ & $16(55.2 \%)$ & $0.009 *$ \\
\hline Local & $41(75.9 \%)$ & $8(50.0 \%)$ & $13(44.8 \%)$ & - \\
\hline \multicolumn{5}{|c|}{ Delayed Repair of Trauma } \\
\hline Yes & $10(19.6 \%)$ & $5(33.3 \%)$ & $8(25.0 \%)$ & 0.491 \\
\hline No & $41(80.4 \%)$ & $10(66.7 \%)$ & $24(75.0 \%)$ & - \\
\hline \multicolumn{5}{|c|}{ Post-operative Aphakia } \\
\hline With & $23(40.4 \%)$ & $8(61.5 \%)$ & $10(35.7 \%)$ & 0.306 \\
\hline Without & $34(59.6 \%)$ & $5(38.5 \%)$ & $18(64.3 \%)$ & - \\
\hline \multicolumn{5}{|c|}{ Number of Surgeries } \\
\hline 0 & $21(25.0 \%)$ & $1(5.6 \%)$ & $5(12.8 \%)$ & 0.062 \\
\hline 1 & 49 (58.3\%) & $13(72.2 \%)$ & $20(51.3 \%)$ & - \\
\hline$\geq 2$ & $14(16.7 \%)$ & $4(22.2 \%)$ & $14(35.9 \%)$ & - \\
\hline
\end{tabular}




\begin{tabular}{|c|c|c|c|c|}
\hline \multicolumn{5}{|c|}{ Subspecialty Referral } \\
\hline Yes & $39(46.4 \%)$ & $10(55.6 \%)$ & $33(84.6 \%)$ & $60.0001^{*}$ \\
\hline No & $45(53.6 \%)$ & $8(44.4 \%)$ & $9(23.1 \%)$ & - \\
\hline External disease referral & $16(19.0 \%)$ & $6(33.3 \%)$ & $2(5.1 \%)$ & 0.391 \\
\hline Glaucoma referral & $4(4.8 \%)$ & $1(5.6 \%)$ & $2(5.1 \%)$ & 0.855 \\
\hline Orbit/Plasty referral & - & - & $4(10.3 \%)$ & 0.162 \\
\hline Pediatric clinic referral & $5(6.0 \%)$ & $4(22.2 \%)$ & $24(61.5 \%)$ & $<.081$ \\
\hline Retina referral & $17(20.2 \%)$ & $4(22.2 \%)$ & $9(23.1 \%)$ & $0.0001^{*}$ \\
\hline Retinal detachment & $3(3.6 \%)$ & $1(5.6 \%)$ & $8(20.5 \%)$ & 0.118 \\
\hline Vitreous hemorrhage & $7(8.3 \%)$ & $1(5.6 \%)$ & $8(20.5 \%)$ & 0.522 \\
\hline Intraocular foreign body & $11(13.1 \%)$ & $2(11.1 \%)$ & $4(10.3 \%)$ & $0.012^{*}$ \\
\hline Endophthalmitis & - & - & & 0.003 \\
\hline
\end{tabular}

Data presented as count (percent)

*Significant at $5 \%$ level

\section{Discussion}

Compared to other studies which report occupation related injuries between $26.1 \%-37 \%$, in this study the rate is higher at $48.6 \%$ (88/181) [6,7]. This may reflect the poor implementation of safety standards for most laborers in the Philippines, despite clear provisions in the Occupational Safety and Health (OSH) manual of the Department of Labor [8]. Majority of patients who consulted at eye center for globe trauma did not use protective eyewear in the workplace and were not provided with adequate safety equipment by their employers. The geographic origins of patients are listed in appendix Table 2, which may serve as a guide to where prevention campaigns on globe trauma may have the most impact.

For children 8 years old and below, most incidents were unintentional and the most common objects causing injury were knives $(7 / 34,20.6 \%)$ followed by pens/pencils (5/34, 14.7\%). This is similar with data from a study on open globe injuries in Iran where they noted knives as the cause for $33.6 \%$ of globe trauma for patients under 7 years old.2 Moreover majority of the incidents happened at home $(25 / 29,86.2 \%)$, compared to at school $(3 / 29$, $10.3 \%$ ). This suggests that more precaution at the household is necessary for children, as commonplace items have led to serious ocular accidents. Childhood ocular trauma is of special concern because secondary visual deprivation amblyopia is responsible for permanent vision loss even if the globe trauma is treated surgically, and complications such as uveitis and glaucoma are common post-operatively [9].

The most common complication noted was IOFB (27/107, $25.2 \%$ ) followed by vitreous hemorrhage (22/174, 20.6\%). In a study done in China on the clinical characteristics and visual outcomes of 1,421 eyes with globe trauma and IOFBs, they published a similar rate of $28.6 \%$ for IOFBs among open-globe trauma (1421/4968 eyes) [10]. The published rates of vitreous hemorrhage are higher in other studies, between 37-51\%.6 The high rates of IOFB may be due to the nature of injuries of our patients, most common of which are hammered nails which may lodge intra ocularly. There were also cases where despite workers using eye protection in the workplace, due to the high velocity nature of the injury the object still penetrated through the protective gear commonly made only of hard plastic. This may prompt a re-evaluation of the quality of safety equipment used.

For subspecialty retina surgeries for posterior pole complications, eyes that underwent removal of IOFB showed significant improvement in VA from initial to last follow-up (Log Mar 1.76 \pm 0.84 vs $1.06 \pm 0.95 ; \mathrm{p}=0.009$ ). Good surgical outcomes for IOFBs may be consistent with the observation of other studies that IOFBs are a good prognostic indicator in globe trauma, as a small penetrating foreign body may only cause minimal structural damage to the eye [11]. Interestingly, their study also commented on how final VA was not associated with immediate removal of the IOFB, and delay of up to several weeks did not affect the VA significantly as long as there was no concurrent endophthalmitis [11]. In our study the mean time to removal of IOFB was $53 \pm 66$ days, showing a long delay and large variation. The observation of other studies showing good results despite delayed removal of IOFB may explain this trend. In comparison, eyes that underwent surgical repair of traumatic retinal detachment did not have significant improvement of VA on last follow-up (Log Mar 1.79 \pm 0.95 vs $1.66 \pm 0.99 ; \mathrm{p}=0.128$ ), as these are usually complicated cases that may have concurrent proliferative vitreoretinopathy, multiple breaks, and choroidal hemorrhage. Patients with significant corneal defects affecting VA were seen by the external disease clinic and were advised for PKP. Interestingly, none have undergone the procedure due to various reasons. Five of the 14 patients were lost to follow-up, while others changed treatment plan to have rigid gas permeable lenses, or close monitoring instead. This may reflect the lack of optical grade cornea prompting the service to do conservative treatment, prioritizing patients with better prognosis. Despite not undergoing PKP, there was a significant improvement in VA from initial consult to last follow-up for this group of patients ( $\log$ MAR $2.07 \pm 0.68$ vs $1.22 \pm 0.94 ; p=0.007$ ), and it may be due to the cornea's capability to heal itself over time, despite the irregular astigmatism from scarring. 
Regarding delayed-onset complications presenting after 1 month of consult, the only cases noted were the development of posterior subcapsular cataract in cases with intact crystalline lens. There were no recorded cases of delayed-onset RD, sympathetic ophthalmia or endophthalmitis after open globe injury. This is interesting because literature suggests that many delayed onset complications happen after globe trauma, such as the published rate of RD that becomes clinically evident only between 1 month and 2 years after the incident [12] The absence of delayed RD maybe because most of the patient population is young, whose eyes have not yet undergone syneresis and this helps prevent fluid from entering through a traumatic break into the subretinal space [12]. Visual outcomes at last follow-up were classified as excellent $(20 / 60$ or better) in $59.6 \%$ of cases (84/141). Roper-hall reported that $45 \%$ of globe trauma with anterior segment injuries led to final VA of $20 / 40$ or better [12]. A more recent study on the visual outcomes of penetrating globe trauma of 176 eyes over a span of 4 years reported $67 \%$ of such injuries had 20/60 final VA or better, which is comparable to our results [13]. With ordinal regression, better initial VA contributed to excellent final VA ( $p=0.006$ [95\% CI 0.3311.930]). This is consistent with other studies that show that one of the strongest predictors of final VA after globe trauma is initial VA [13-15].

This study can be used as a basis for the development of a trauma registry that can create a more accurate picture of ocular trauma in the country. Use of the Ocular Trauma Score with a corresponding standardized ocular trauma form may help with data for better comparison across different institutions. The authors also recommend having collaboration with the industrial sector. Workplace strategies to prevent globe trauma should be developed, as workers are high-risk groups who usually do not report having adequate eye protection upon inquiry. Prevention of injuries is important because most patients are adult males who may be the primary breadwinner of the family, with poor vision significantly impacting their ability to earn. Awareness and safety campaigns in communities may also help decrease injuries within the household where most open-globe trauma among children occurs. For clinicians these results can be used as a guide regarding outcomes and complications. Counseling of families prior to obtaining consent for surgery or outpatient management should be based on the patient's prognosis and presenting clinical picture.

This study was conducted at a single tertiary eye care center where population sampling may be limited. In addition, not all patients presenting with open-globe trauma from January 2013 to November 2017 were included due to missing charts from the database. Since this is a retrospective study, the study is also limited to the data found in the charts. To address these limitations, future prospective, multi-center studies may be done to increase the sample size and minimize the amount of missing data for collection.

\section{Conclusion}

Implementing policies for the prevention of ocular trauma should be a priority for eye care programs. Employers and government agencies should have an evaluation of eye protection used in the workplace, as most injuries are still accidents at industrial areas during working hours, involving personnel without adequate equipment. Awareness and safety campaigns in communities may also help decrease injuries within the household where most openglobe trauma among children occurs. Counseling patients with regards to proper management and prognosis should be based on initial VA, complications, and other pertinent clinical characteristics.

\section{Acknowledgements}

The authors would like to thank the East Avenue Medical Center Department of Ophthalmology consultants and staff for their support to this research project.

\section{Conflicts of Interest}

No Conflict of Interest.

\section{References}

1. Kuhn F, Morris R, Witherspoon CD (2004) Birmingham Eye Trauma Terminology system (BETT). J Fr Ophtalmol 27(2): 206-210.

2. Xi Z, Yuqing L, Xiangning J (2017) A Retrospective Study on Clinical Features and Visual Outcome of Patients Hospitalized for Ocular Trauma in Cangzhou, China. Hindawi Journal of Ophthalmology.

3. Mansouri M, Faghihi H, Hajizadeh F, Rasoulinejad SA, Rajabi MT, et al. (2009) Epidemiology of open-globe injuries in iran: Analysis of 2,340 cases in 5 years (report no. 1). Retina 29(8): 1141-1149.

4. Lange C, Feltgen N, Junker B, Schulze-Bonsel K, Bach M (2009) Resolving the clinical acuity categories "hand motion" and "counting fingers" using the Freiburg Visual Acuity Test (FrACT). Graefes Arch Clin Exp Ophthalmology 247(1): 137-142.

5. Kuhn F, Maisiak R, Mann L, Mester V, Morris R, et al. (2002) The ocular trauma score (OTS). Ophthalmol Clin North Am 15(2): 163-165.

6. Smith D, Wrenn K, Stack LB (2002) The epidemiology and diagnosis of penetrating eye injuries. Acad Emerg Med 9(3): 209 -213.

7. Byhr E (1994) Perforating eye injuries in a western part of Sweden. Acta Ophthalmol (Copenh) 72(1): 91-97.

8. (1990) Department of Labor and Employment Manila. Occupational Safety and Health Standards Manual Rule 1080: 34-35.

9. (2017) Basic and Clinical Science Course 2016-2017. Chapter 6: Pediatric Ophthalmology and Strabismus. American Academy of Ophthalmology 6: 70 .

10. Zhang Y, Zhang M, Jiang C, Qiu HY (2011) Intraocular Foreign Bodies in China: Clinical Characteristics, Prognostic Factors, and Visual Outcomes in 1421 Eyes. Am J Ophthalmol 152(1): 66-73.

11. (2017) Basic and Clinical Science Course 2016-2017. Chapter 12: Retina and Vitreous. American Academy of Ophthalmology 12: 332.

12. Roper-Hall MJ (1959) The treatment of ocular injuries. Trans Ophthalmol Soc UK 79: 57-92.

13. Esmaeli B, Elner SG, Schork MA, Elner VM (1995) Visual Outcome and Ocular Survival after Penetrating Trauma: A Clinicopathologic Study. Ophthalmology 102(3): 393-400. 
14. Gervasio KA, Weinstock BM, Wu AY (2015) Prognostic Value of Ocular Trauma Scores in Patients with Combined Open Globe Injuries and Facial Fractures. Am J Ophthalmol 160(5): 882-888.
15. Rahman I, Maino A, Devadason D, Leatherbarrow B (2006) Open globe injuries: factors predictive of poor outcome. Eye (Lond) 20(12): 13361341. 